\title{
Coexistence of familial Mediterranean fever and Behçet's disease: a case report
}

\author{
Tuba Güler, ${ }^{1}$ Yeşim Garip, ${ }^{2}$ Fulya Dörtbaş, ${ }^{3}$ Ayşse Aslıhan Karcı, ${ }^{4}$ Nurşad Çifçi ${ }^{5}$ \\ ${ }^{1}$ Department of Physical Medicine and Rehabilitation, Derince Training and Research Hospital, Kocaeli, Turkey \\ ${ }^{2}$ Department of Physical Medicine and Rehabilitation, Başak Medical Center, Ankara, Turkey \\ ${ }^{3}$ Department of Rheumatology, Derince Training and Research Hospital, Kocaeli, Turkey \\ ${ }_{4}^{4}$ Department of Ophtalmology, Derince Training and Research Hospital, Kocaeli, Turkey \\ ${ }^{5}$ Department of Dermatology, Derince Training and Research Hospital, Kocaeli, Turkey \\ Received: October 2014 Accepted: March 2015
}

\begin{abstract}
Behçet's disease (BD) is a chronic, multi-systemic vasculitis, characterized by a triad of recurrent aphthous stomatitis, genital aphthae, and uveitis. It is common in the Eastern Mediterranean, Middle East, and Eastern Asian countries. Familial Mediterranean fever (FMF) is an autosomal recessive autoinflammatory disorder, which is common seen in the Turkish, Armenian, Arabic, and Sephardic Jewish populations. It is characterized by recurrent episodes of fever, peritonitis, pleuritis, arthritis, and erysipelas-like skin lesions. Behçet's disease and FMF have common clinical features and geographic distribution. Herein, we present a 19-year-old female patient with coexistence of FMF and BD in the light of literature data.
\end{abstract}

Keywords: Behçet's disease; Familial Mediterranean fever; hereditary autoinflammatory diseases.

Behçet's disease (BD) is a chronic, multi-systemic vasculitis of every size and type vessels. It was first described by Hulusi Behçet, a Turkish Professor of Dermatology, in 1937, as a triad of recurrent aphthous stomatitis, genital aphthae, and relapsing uveitis. ${ }^{[1]}$ The prevalence of BD is highest in the countries of the Eastern Mediterranean, Middle East, and Eastern Asian rim. ${ }^{[2]}$

Familial Mediterranean fever (FMF) is an autoinflammatory disorder characterized by periodic fever and serosal inflammation. ${ }^{[3]}$ It is common in the Turkish, Armenian, Arabic, and Sephardic Jewish populations. ${ }^{[4]}$ The Mediterranean Fever (MEFV) gene, associated with FMF, is located on chromosome 16 and encodes a 781-amino-acid protein termed pyrin. ${ }^{[5]}$

Behçet's disease and FMF share a number of features in common in terms of clinical features and geographic distribution. Several studies have suggested that MEFV mutations may be associated with $\mathrm{BD} .^{[1,6-9]}$
Herein, we report a case of coexistence of FMF and $\mathrm{BD}$, and to discuss the immunopathogenetic mechanisms for possible associations among these two autoinflammatory diseases.

\section{CASE REPORT}

A 19-year-old female with a 10-year history of BD was referred to our outpatient rheumatology clinic with bilateral ankle joint arthritis, abdominal pain, and fever. The patient presented with a history of two years of recurrent attacks for fever, abdominal pain, and arthralgia for about four days. She was admitted to our emergency room with these complaints two days ago. She was followed for 24 hours, and no other pathology which could explain abdominal pain and infection findings for fever were able to be found. Therefore, she was referred to our outpatient rheumatology clinic. In the records of emergency room, fever was $39^{\circ} \mathrm{C}$, and laboratory 
test results were as follows: C-reactive protein (CRP): $89.9 \mathrm{mg} / \mathrm{L}$ (normal range: $0.00-5.00 \mathrm{mg} / \mathrm{L}$ ), white blood cell count (WBC): $14,000 / \mathrm{mm}^{3}$ (normal range: $4000-11,000 / \mathrm{mm}^{3}$ ), hemoglobin: $11 \mathrm{mg} / \mathrm{dL}$ (normal range: $12-14 \mathrm{mg} / \mathrm{dL}$ ), platelet count: $311,000 / \mathrm{mm}^{3}$ (normal range: $150,000-400,000 / \mathrm{mm}^{3}$ ). Biochemistry test results were within normal ranges. She was under therapy with colchicine $1.5 \mathrm{mg}$ /day and diclofenac $100 \mathrm{mg} /$ day. A written informed consent was obtained from the patient.

In her past medical history obtained using the patient's file, she was diagnosed with BD 10 years ago in another medical institution, when was admitted with recurrent oral aphthae one to two times a month, recurrent genital ulcers, and tender and reddish lesions on her legs. She was diagnosed with erythema nodosum by the treating physician. The pathergy skin test result was positive, and she was diagnosed with BD. She was prescribed colchicine $1.5 \mathrm{mg} /$ day. The patient described recurrent oral aphthae (three times within the past one month) and genital ulcers, despite colchicine therapy.

On admission, her physical examination revealed a body temperature of $39.5^{\circ} \mathrm{C}$. She did not have any oral aphthae or genital ulcer. Bilateral ankles were swollen, reddish, painful, and tender to palpation. The ranges of motion of lumbar spine and ankles were normal. The modified Schober test was $4.5 \mathrm{~cm}$. The Mennel, Gaenslen, and sacroiliac compression tests were bilaterally negative. Neurological examination findings were normal.

Laboratory tests one week later showed the following: erythrocyte sedimentation rate (ESR): $70 \mathrm{~mm} / \mathrm{h}$ (normal range: $0.00-27 \mathrm{~mm} / \mathrm{h}$ ), CRP: $15 \mathrm{mg} / \mathrm{L}$ (normal range: $0.00-4.99 \mathrm{mg} / \mathrm{L}$ ), WBC: $11,000 / \mathrm{mm}^{3}$ (normal range: $4,000-11,000 / \mathrm{mm}^{3}$ ). Biochemistry test results were within normal ranges. Human leukocyte antigen (HLA)-B27 and rheumatoid factor (RF) were negative.

Due to the lack of infection, deep venous thrombosis or thrombophlebitis which can explain fever in BD, normal views in the posteroanterior chest graphy, and coexistence of fever and abdominal pain for about four days, we suspected FMF.

The patient was diagnosed with FMF, based on the clinical course and the exclusion of other diseases. She fulfilled the Livneh criteria for FMF. ${ }^{[10]}$ Colchicine dose was increased to $2 \mathrm{mg} /$ day. Methylprednisolone $16 \mathrm{mg} /$ day, azathioprine $100 \mathrm{mg} /$ day, and diclofenac sodium $150 \mathrm{mg} /$ day were added to treatment. Azathioprine was added, due to recurrent oral aphthae and genital ulcers, despite colchicine therapy.

Molecular analysis was performed by sequencing of exon 2, 3, 5, and 10 of MEFV gene. Genetic analysis for the MEFV gene revealed a compound heterozygous mutation (M694V/R202Q). At her first follow-up visit at one month, her symptoms relieved with improved mucocutaneous ulcerations. In addition, ESR and CRP returned to normal. Methylprednisolone dose was gradually decreased to $8 \mathrm{mg} / \mathrm{day}$. At her follow-up visit at six months, oral aphthae were not observed. During six-month period, we observed genital ulcer one time and fever and abdominal pain attack two times. With the medical treatment, the patient reported a significant reduction in the number of attacks and improvement in the severity of attacks.

\section{DISCUSSION}

Behçet's disease is a multi-genetic inflammatory systemic disorder of unknown etiology. ${ }^{[1]}$ Clinical features include oral and genital ulcers, cutaneous lesions, and ophthalmologic, neurologic, and gastrointestinal manifestations. ${ }^{[12]}$ Familial Mediterranean fever is a multi-system disease characterized by recurrent and self-limiting attacks of fever and serositis. ${ }^{[13]}$ Musculoskeletal involvement such as arthritis, arthralgia, enthesitis, and sacroiliitis can be also seen in the course of FMF. ${ }^{[14]}$

Our case fulfilled the Livneh Diagnostic Criteria for FMF, ${ }^{[10]}$ and the International Study Group Criteria for $\mathrm{BD}^{[15]}$ She was heterozygous for M694V/R202Q mutation. Matsuda et al. ${ }^{[16]}$ reported a 15 -year-old Japanese male patient who presented with multiple buccal aphthoses, genital ulcers, and iridouveitis as manifestations of $\mathrm{BD}$ and the attacks of fever and thoracoabdominal pain as clinical features of FMF. The patient was heterozygous for E148Q/M694I mutation. The HLA-B51 and pathergy skin test results were negative. They, therefore, suggested that MEFV mutation might contribute to the development of BD. In another report, Birlik et al. ${ }^{[17]}$ described a 37-year-old Turkish man who presented with attacks of abdominal pain and fever as clinical symptoms of FMF and oral aphthae, genital ulcers, and erythema nodosum as the features of $\mathrm{BD}$. In addition, the patient had sacroiliitis. The pathergy test result was positive. The HLA-B5 test result was negative. Mobini ${ }^{[18]}$ also reported a 27 -yearold Iranian man with a five-year history of BD. He presented with attacks of fever, chills, arthralgia, and arthritis. His pathergy test result was positive, and 
genetic analysis showed a compound heterozygote mutation E148Q/P369S in the MEFV gene.

Clinical findings and geographic distribution of FMF and BD share a number of features in common. ${ }^{[1]}$ It is, however, still a matter of debate whether MEFV mutations have a role in the development of $\mathrm{BD}$. Higher frequencies of MEFV mutations in BD patients were first reported in 2000 by Touitou et al. ${ }^{[6]}$ who found that M694V, V726A, and E148Q mutations were more frequent in $\mathrm{BD}$, suggesting that these mutations might act as susceptibility factors in BD. In addition, Imirzalioglu et $a .^{[7]}$ found the frequency of MEFV mutations (M694V, E148Q and M680I) in BD as $35.7 \%$. Of these mutations, M694V and E148Q were significantly higher in the patient group than in the controls. They suggested that these mutations might be linked with the pathogenesis of $\mathrm{BD}$ and recommended that further studies were needed to assess newer mutations associated with BD by sequencing all coding regions of the pyrin gene. In the study of Yazici et al. ${ }^{[1]}$ where $100 \mathrm{BD}$ patients were assessed, MEFV mutations (M694V, E148Q, M680I and V726A) were detected in $27 \%$ of the patients. The most frequent mutation was M694V with an allelic frequency of $5 \%$. Additionally, they evaluated the relationship between the mutations and clinical findings of BD; however, they were able to find no relationship. Esmaeili et al. ${ }^{\left[{ }^{[8]}\right.}$ reported that $36 \%$ of Azeri Turkish patients in Iran had MEFV gene mutations, and suggested that M694V and M680I mutations might be additional genetic susceptibility factors in BD. In a study of Ayesh et al., ${ }^{[9]}$ in 42 Palestinian BD patients, the frequency of MEFV mutations was found to be $40.5 \%$ with E148Q being the most prevalent mutation. The authors concluded that there might be an association between MEFV mutations and the development of $\mathrm{BD}$. In the study of Rabinovich et al., ${ }^{[19]} 54$ BD patients were genotyped for the three most frequent MEFV mutations (i.e., M694V, V726A and E148Q). The authors found MEFV as a susceptibility and modifier gene in BD. Tasliyurt et al. ${ }^{[20]}$ also described the rate of MEFV mutations in Turkish BD patients as 39\%, suggesting that E148Q and M680I mutations might have a role in the pathogenesis of BD. Surprisingly, the aforementioned authors found significantly lower rates of uveitis in $\mathrm{BD}$ patients without MEFV mutations, compared to those without a mutation, suggesting that MEFV mutation might provide protection against uveitis. Schwartz et al. ${ }^{[21]}$ conducted a retrospective study in which FMF patients also suffering from $\mathrm{BD}$. They found a higher prevalence of BD in the patients with FMF, compared to normal population. They suggested that BD and FMF might occur in the same individual more commonly than expected.

On the other hand, Espinosa et al. ${ }^{[22]}$ conducted a study in 50 Spanish patients with $\mathrm{BD}$, and found no association between MEFV mutation and BD. They suggested that MEFV mutations detected in BD patients were probably resulting from ethnic origin of the groups. Similarly, Ben-Chetrit et al. ${ }^{[23]}$ reported that FMF and BD were two different disorders which had a mild trend toward a higher than the expected association. There was no mutual effect of FMF on $\mathrm{BD}$, or vice versa. In a review by Aksu and Keser, ${ }^{[24]}$ it was concluded that FMF and BD probably coexisted by chance, as both of them had common geographic distribution and similar clinical characteristics.

To the best of our knowledge, there is no study to demonstrate a relationship between R202Q mutation and BD, therefore, we are of the opinion that M694V mutation may be associated with the development of $\mathrm{BD}$ in our case.

In conclusion, $\mathrm{BD}$ and FMF are two autoinflammatory diseases which share common features such as geographic distribution and clinical manifestations. The MEFV mutations may be one of responsible factors in the development of BD. However, further large-scale studies are needed to demonstrate the role of MEFV mutations in the pathogenesis of $\mathrm{BD}$.

\section{Declaration of conflicting interests}

The authors declared no conflicts of interest with respect to the authorship and/or publication of this article.

\section{Funding}

The authors received no financial support for the research and/or authorship of this article.

\section{REFERENCES}

1. Yazici A, Cefle A, Savli H. The frequency of MEFV gene mutations in Behcet's disease and their relation with clinical findings. Rheumatol Int 2012;32:3025-30.

2. Srivastava N, Chand S, Bansal M, Srivastava K, Singh S. Familial Behcet's disease. Indian J Dermatol Venereol Leprol 2007;73:260-1.

3. Yokota K, Fukuda M, Migita K, Tanaka E, Okamoto T, Kimura K. Three patients with familial Mediterranean fever: a possible underdiagnosed entity in Japan. Intern Med 2014;53:2013-6.

4. Cazeneuve C, Hovannesyan Z, Geneviève D, Hayrapetyan H, Papin S, Girodon-Boulandet E, et al. Familial Mediterranean fever among patients from Karabakh and the diagnostic value of MEFV gene analysis in all classically affected populations. Arthritis Rheum 2003;48:2324-31.

5. Berkun Y, Eisenstein EM. Diagnostic criteria of familial Mediterranean fever. Autoimmun Rev 2014;13:388-90. 
6. Touitou I, Magne X, Molinari N, Navarro A, Quellec AL, Picco P, et al. MEFV mutations in Behçet's disease. Hum Mutat 2000;16:271-2.

7. Imirzalioglu N, Dursun A, Tastan B, Soysal Y, Yakicier MC. MEFV gene is a probable susceptibility gene for Behçet's disease. Scand J Rheumatol 2005;34:56-8.

8. Esmaeili M, Bonyadi M, Khabbazi A, Ebrahimi AA, Sharif SK, Hajialilo M, et al. Common MEFV mutations in Iranian Azeri Turkish patients with Behçet's disease. Scand J Rheumatol 2011;40:383-6.

9. Ayesh S, Abu-Rmaileh H, Nassar S, Al-Shareef W, Abu-Libdeh B, Muhanna A, et al. Molecular analysis of MEFV gene mutations among Palestinian patients with Behcet's disease. Scand J Rheumatol 2008;37:370-4.

10. Livneh A, Langevitz P, Zemer D, Zaks N, Kees S, Lidar T, et al. Criteria for the diagnosis of familial Mediterranean fever. Arthritis Rheum 1997;40:1879-85.

11. Saleh Z, Arayssi T. Update on the therapy of Behçet disease. Ther Adv Chronic Dis 2014;5:112-34.

12. Melikoglu M, Melikoglu MA. The prevalence of fibromyalgia in patients with Behçet's disease and its relation with disease activity. Rheumatol Int 2013;33:1219-22.

13. Melikoglu M, Melikoglu MA. The prevalence of fibromyalgia in patients with Behçet's disease and its relation with disease activity. Rheumatol Int 2013;33:1219-22.

14. Kaşifoğlu T, Calişir C, Cansu DU, Korkmaz C. The frequency of sacroiliitis in familial Mediterranean fever and the role of HLA-B27 and MEFV mutations in the development of sacroiliitis. Clin Rheumatol 2009;28:41-6.

15. Criteria for diagnosis of Behçet's disease. International Study Group for Behçet's Disease. Lancet 1990;335:1078-80.
16. Matsuda M, Nakamura A, Tsuchiya S, Yoshida T, Horie S, Ikeda S. Coexistence of familial Mediterranean fever and Behçet's disease in a Japanese patient. Intern Med 2006;45:799-800.

17. Birlik M, Tunca M, Hizli N, Soytürk M, Yeniçerioğlu Y, Ozcan MA, et al. Coexistence of familial Mediterranean fever with sacroiliitis and Behçet's disease: a rare occurrence. Clin Rheumatol 1998;17:397-9.

18. Mobini M. Familial mediterranean fever in an Iranian patient with behcet disease. Caspian J Intern Med 2011;2:344-6.

19. Rabinovich E, Shinar Y, Leiba M, Ehrenfeld M, Langevitz P, Livneh A. Common FMF alleles may predispose to development of Behcet's disease with increased risk for venous thrombosis. Scand J Rheumatol 2007;36:48-52.

20. Tasliyurt T, Yigit S, Rustemoglu A, Gul U, Ates O. Common MEFV gene mutations in Turkish patients with Behcet's disease. Gene 2013;530:100-3.

21. Schwartz T, Langevitz P, Zemer D, Gazit E, Pras M, Livneh A. Behçet's disease in Familial Mediterranean fever: characterization of the association between the two diseases. Semin Arthritis Rheum 2000;29:286-95.

22. Espinosa G, Arostegui JI, Plaza S, Rius J, Cervera R, Yagüe J, et al. Behçet's disease and hereditary periodic fever syndromes: casual association or causal relationship? Clin Exp Rheumatol 2005;23:64-6.

23. Ben-Chetrit E, Cohen R, Chajek-Shaul T. Familial mediterranean fever and Behçet's disease--are they associated? J Rheumatol 2002;29:530-4.

24. Aksu K, Keser G. Coexistence of vasculitides with familial Mediterranean fever. Rheumatol Int 2011;31:1263-74. 